\title{
Growth Inhibition by Purine Derivatives and Its Reversal by Pyrimidine Derivatives in a Mutant of Escherichia coli K12
}

\author{
Makoto ShimosaKa, ${ }^{*}$ Yasuki FukudA, Kousaku Murata \\ and Akira KIMURA \\ Research Institute for Food Science, Kyoto University, \\ Uji, Kyoto 611, Japan \\ Received November 30, 1983
}

\begin{abstract}
An adenosine-sensitive mutant was isolated from Escherichia coli $\mathrm{K} 12$ derivative strain C600. This mutant (designated as PS100) grew slower than parental strain C600 in a minimal medium, and its growth was completely inhibited by addition of all kinds of purine bases, nucleosides and nucleotides tested. On the other hand, this growth inhibitory effect of purine derivatives was reversed by co-addition of uridine to the medium. Other pyrimidine derivatives such as uracil, UMP, cytosine, cytidine, CMP and thymidine were also effective for this reversal. The mutant strain, PS100, showed a lower level $(7 \%)$ of activity for orotate phosphoribosyltransferase than strain C600 did, and accumulated orotic acid in the growth medium. Lysogenization of strain PS100 with $\lambda$ transducing phage containing the gene for orotate phosphoribosyltransferase ( $p y r E$ ) resulted in restoration of the activity for orotate phosphoribosyltransferase and removal of growth inhibition by purine derivatives.
\end{abstract}

In $E$. coli, exogenous purine and purine nucleosides were utilized for the synthesis of purine nucleotides through a purine salvage pathway. ${ }^{1)}$ Inhibition of cell growth by exogenous adenine or adenosine was reported in E. coli, ${ }^{2,3)}$ Staphylococcus aureus, ${ }^{4)}$ mouse fibroblasts $^{5)}$ and human lymphoblasts. ${ }^{6}$ Inhibitory effects of these purine bases and nucleosides have been considered to be related with feedback inhibition of the purine de novo biosynthetic pathway, especially in the reaction step catalyzed by 5'-phosphoribosyl 1'-pyrophosphate amidotransferase. ${ }^{1,7)}$ However, an other mechanism of inhibition has been postulated. Some workers stated that such growth inhibition might be due to a "purine-pyrimidine imbalance" caused by exogenous purine derivatives, ${ }^{3,5,8)}$ although the mechanism was not clarified in detail.

We have isolated an adenosine-sensitive mutant from $E$. coli $\mathrm{K} 12$ derivative strain C600. This mutant (designated as PS100) was also sensitive to all kinds of purine bases, nucle- osides and nucleotides tested. Inhibitory effects of such purine derivatives on growth of PS100 were reversed by co-addition of pyrimidine derivatives. Therefore, it is of interest to investigate this growth inhibitory effect of purine derivatives from the standpoint of the regulation of the purine salvage pathway and the intracellular balance between purine and pyrimidine derivatives.

In this study, growth characteristics of mutant PS100 were examined and the activity of orotate phosphoribosyltransferase [E.C. 2.4.2.10] was assayed as an enzyme responsible for the phenotypic characters of the mutant.

\section{MATERIALS AND METHODS}

Strains and media. E. coli $\mathrm{K} 12$ strain $\mathrm{C} 600\left(\mathrm{~F}^{-}\right.$, leu, thr, thi, lac $Y$, supE, ton $A, \mathrm{r}_{\mathrm{K}}^{-}, \mathrm{m}_{\mathrm{K}}{ }^{-}$) and Davis-Mingioli minimal medium ${ }^{9)}\left[0.7 \% \mathrm{KH}_{2} \mathrm{PO}_{4}, 0.2 \% \mathrm{~K}_{2} \mathrm{HPO}_{4} 0.01 \%\right.$ $\left(\mathrm{NH}_{4}\right)_{2} \mathrm{SO}_{4}, 0.2 \%$ glucose (citrate free)] supplemented with $10 \mu \mathrm{g} / \mathrm{ml}$ leucine, $50 \mu \mathrm{g} / \mathrm{ml}$ threonine and $1 \mu \mathrm{g} / \mathrm{ml}$ thiamine were used throughout this study. In case of mutant

Abbreviations: P-Rib-PP, 5'-phosphoribosyl 1'-pyrophosphate; OPT, orotate phosphoribosyltransferase; OMPDC, orotidine 5'-monophosphate decarboxylase 
selection, the same medium containing $10 \mathrm{~mm}$ adenosine as a nitrogen source was used in place of $\left(\mathrm{NH}_{4}\right)_{2} \mathrm{SO}_{4}$. The $\lambda$ pyrE-dut transducing phage used was BW106, which was constructed by Taylor et al. ${ }^{10)}$ and kindly donated by Dr. T. Komano of Kyoto University. Phage purification, immunity testing and transduction were done according to the methods of Miller. ${ }^{11)}$

Mutagenesis. Mutation of E. coli $\mathrm{C} 600$ was carried out according to the method of Adelberg et al. ${ }^{12)}$ E. coli $\mathrm{C} 600$ cells cultured in LB broth ( $1 \%$ Bacto-peptone, $0.5 \%$ yeast extract, $0.5 \% \mathrm{NaCl}, 0.1 \%$ glucose, $\mathrm{pH} 7.2)$ to the midlogarithmic phase were harvested, washed once with $5 \mathrm{~mm}$ potassium phosphate buffer (pH.6.0) and then suspended in $2 \mathrm{ml}$ of the same buffer containing $100 \mu \mathrm{g} / \mathrm{ml}$ of $N$ methyl- $N^{\prime}$-nitro- $N$-nitrosoguanidine (NTG). After incubation at $30^{\circ} \mathrm{C}$ for $30 \mathrm{~min}$ with shaking, a $50 \mu \mathrm{l}$ portion of this cell suspension was transferred to $5 \mathrm{ml}$ of LB broth and the cells were incubated at $37^{\circ} \mathrm{C}$ overnight. Cells were harvested, washed twice with $0.85 \%$ saline solution and finally suspended in $5 \mathrm{ml}$ of the same solution. A $100 \mu \mathrm{l}$ portion of this cell suspension was transferred to $5 \mathrm{ml}$ of minimal medium containing adenosine $(10 \mathrm{~mm})$ in place of $\left(\mathrm{NH}_{4}\right)_{2} \mathrm{SO}_{4}$. After incubation at $37^{\circ} \mathrm{C}$ for $5 \mathrm{hr}$, penicillin $\mathrm{G}$ was added to a final concentration of 200 units $/ \mathrm{ml}$ and incubation was continued for a further $4 \mathrm{hr}$ at $37^{\circ} \mathrm{C}$. Aliquots of this cell culture were spread on minimal agar $(1.5 \%)$ plates and the plates were incubated at $37^{\circ} \mathrm{C}$ for 2 days. The colonies appearing on the plates were replicated on minimal agar plates containing $10 \mathrm{~mm}$ adenosine in place of $\left(\mathrm{NH}_{4}\right)_{2} \mathrm{SO}_{4}$, and the colonies incapable of growing on the plates were selected as mutants. One of them was designated as PS100.

Purification of $U V$-absorbing material from the culture fluid. Cells of strain PS100 cultured in $500 \mathrm{ml}$ of minimal medium to the late-logarithmic phase were removed by centrifugation for $10 \mathrm{~min}$ at $8,000 \times g$. The resultant supernatant $(410 \mathrm{ml})$ was adjusted to $\mathrm{pH} 4.0$ with $6 \mathrm{~N}$ hydrochloric acid. Optical densities at $260 \mathrm{~nm}$ and $280 \mathrm{~nm}$ (O.D. 260 and O.D. 280) of this solution were 1.8 and 2.5 , respectively, and the total optical density at $260 \mathrm{~nm}$ [O.D.U. 260, O.D. $260 \times$ volume $(\mathrm{ml})$ ] was 738 . Then $750 \mathrm{mg}$ of active charcoal (Norit A) was added to this solution and the mixture incubated at $37^{\circ} \mathrm{C}$ for $20 \mathrm{~min}$ with vigorous shaking. The Norit A collected by filtration was washed once with $0.001 \mathrm{~N}$ hydrochloric acid containing $0.01 \%$ ethylenediamine tetraacetic acid (EDTA), and suspended in $50 \mathrm{ml}$ of $50 \%$ ethanol containing $0.2 \%$ $\mathrm{NH}_{4} \mathrm{OH}$. This suspension was incubated at $37^{\circ} \mathrm{C}$ for 20 min with vigorous shaking and Norit A was removed by filtration. The resultant filtrate $(50 \mathrm{ml}$, O.D. $260=9.2$, O.D. $280=13.6$, O.D.U. $260=460$ ) was concentrated to a volume of $5.0 \mathrm{ml}$ on a rotary evaporator. The concentrated solution $(5.0 \mathrm{ml})$ was applied to a Dowex $1 \times 2\left(\mathrm{Cl}^{-}\right.$ form, $200 \sim 400 \mathrm{mesh})$ column $(1 \mathrm{~cm} \times 10 \mathrm{~cm})$ and absorbed nucleotides were eluted stepwisely with $50 \mathrm{ml}$ of hy- drochloric acid at increasing concentrations of $0,10,50$, 100 and $500 \mathrm{~mm}$. Most of the UV-absorbing material was eluted as a single peak with $100 \mathrm{~mm}$ hydrochloric acid, and fractions of this peak were pooled $(48 \mathrm{ml}$, O.D. $260=$ 4.9 , O.D. $280=8.3$, O.D.U. $260=235$ ). The O.D.U. 260 recovered was $32 \%$ of that obtained with the original culture fluid. The solution was concentrated to a volume of $5 \mathrm{ml}$ with a rotary evaporator. A white crystal ( $c a .20 \mathrm{mg}$ ) separated out from the solution kept at $4^{\circ} \mathrm{C}$ overnight.

Preparation of crude extract. Cells grown in minimal medium to the late-logarithmic phase were harvested, washed twice with $5 \mathrm{~mm}$ Tris-hydrochloride buffer $(\mathrm{pH}$ 7.6) and suspended in the same buffer. The cell suspension was treated with an ultra sonicator (Kubota Model $200 \mathrm{M}$ ). Cell debris was discarded after centrifugation at $16,000 \times \mathrm{g}$ for $30 \mathrm{~min}$, and the supernatant thus prepared was dialyzed against 100 volumes of $5 \mathrm{~mm}$ Tris-hydrochloride buffer $\left(\mathrm{pH} \mathrm{7.6)}\right.$ at $4^{\circ} \mathrm{C}$ overnight. Protein was determined by the method of Lowry et al. ${ }^{13)}$

Enzyme assays. Orotate phosphoribosyltransferase (OPT) was assayed by the method of Brown and O'Sullivan $^{14)}$ with some modifications. The reaction was carried out in a $5 \mathrm{ml}$ mixture containing $50 \mathrm{~mm}$ Trishydrochloride ( $\mathrm{pH} 8.0), 0.2 \mathrm{mM}(250 \mathrm{nCi})$ [carboxyl${ }^{14} \mathrm{C}$ ]orotic acid, $1 \mathrm{~mm} \mathrm{MgCl}_{2}, 2 \mathrm{~mm}$ 5'-phosphoribosyl 1'pyrophosphate (PRib-PP), 0.1 units of yeast orotidine $5^{\prime}$ monophosphate decarboxylase and crude extract $(2 \sim 5 \mathrm{mg}$ protein) at $37^{\circ} \mathrm{C}$ for 5 to $10 \mathrm{~min}$. The reaction was initiated by addition of the crude extract and terminated with $0.8 \mathrm{ml}$ of $4 \%$ perchloric acid. Radioactive $\mathrm{CO}_{2}$ evolved was absorbed to $\beta$-phenylethylamine in an apparatus devised by Iwai and Taguchi. ${ }^{15)}$ Specific activity was defined as radioactivity $(\mathrm{cpm})$ of $\mathrm{CO}_{2}$ evolved per minute per mgprotein.

Orotidine 5'-monophosphate decarboxylase (OMPDC) was assayed by the method of Lieberman et al. ${ }^{16)}$ One unit of enzyme activity was calculated from the initial reaction rate ( 0 to 4 minutes) and expressed as the amount catalyzing the decarboxylation of $1 \mu \mathrm{mol}$ of orotidine 5 monophosphate in $1 \mathrm{hr}$.

Chemicals. Purine and pyrimidine derivatives were purchased from Kojin Co., Ltd. Japan. [carboxyl- ${ }^{14} \mathrm{C}$ ] Orotic acid was purchased from New England Nuclear Co. Tetrasodium 5'-phosphoribosyl 1'-pyrophosphate (P-RibPP) and penicillin $G$ potassium salt were obtained from $P$ L Biochem. Co. Tubercidin, formycin A, cordycepin and orotidine 5'-monophosphate decarboxylase (from baker's yeast) were the products of Sigma Chemical Co.

\section{RESULTS}

\section{Isolation of a mutant sensitive to purine de- rivatives}

At first, isolation of a mutant deficient in 
adenosine deaminase activity was attempted. Since strain C600 grew well in minimal medium supplemented with adenosine as a sole nitrogen source at a concentration of $10 \mathrm{~mm}$, mutant cells incapable of growing in this medium may be considered to be of a putative adenosine deaminase less mutant. A mutant which could grow on minimal agar medium containing $\left(\mathrm{NH}_{4}\right)_{2} \mathrm{SO}_{4}$ but not on the medium containing adenosine was obtained. But further investigation revealed that the mutant was not deficient in adenosine deaminase activity but was sensitive to adenosine, since the mutant obtained could not grow even in minimal medium containing both $\left(\mathrm{NH}_{4}\right)_{2} \mathrm{SO}_{4}$ and adenosine (10 mM) as nitrogen sources.

This mutant strain was designated as PS100, and the inhibitory effect of adenosine on growth of PS100 was further characterized. Strain PS100 grew slower than parental strain C600 did in minimal medium (the generation time of PS100 was $150 \mathrm{~min}$, while that of C600 was $100 \mathrm{~min}$ at $30^{\circ} \mathrm{C}$ ) (Fig. 1A). Addition of adenosine to a concentration of $10 \mathrm{~mm}$ completely inhibited the growth of PS100. No growth of PS100 was observed for at least $10 \mathrm{~h}$, while the growth of C600 was not inhibited under the same conditions (Fig. 1A). This growth inhibition was also observed when adenosine $(10 \mathrm{~mm})$ was added to the medium at the logarithmic phase, although a slight increase in absorbancy occurred (Fig. 1B). During the period of growth inhibition, no decrease in the viable cell number in the culture was observed for at least $6 \mathrm{hr}$ (data not shown).

Minimal concentrations required for growth inhibition of PS100 were determined for adenosine, adenine, AMP, ADP and ATP. Adenosine inhibited the growth of PS100 at an extremely low concentration $(0.6 \mu \mathrm{M})$. Adenine was also inhibitory at a concentration of $2.5 \mu \mathrm{M}$. AMP, ADP and ATP also inhibited the growth of PS100, but a high concentration $(40 \mu \mathrm{M})$ was needed for all these nucleotides. On the other hand, the growth of C600 was not inhibited by these adenine derivatives at concentrations up to $10 \mathrm{~mm}$.

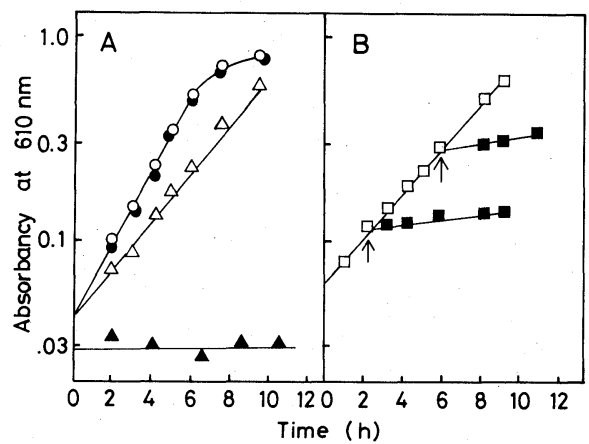

FIG. 1. Growth Curves of PS100 and C600 with and without Addition of Adenosine.

Cells were cultured in minimal medium at $30^{\circ} \mathrm{C}$ with shaking. Adenosine was added at a concentration of $10 \mathrm{~mm}$. (A) PS100 with $(\mathbf{\Delta})$ and without $(\triangle)$ adenosine; C600 with (O) and without $(O)$ adenosine. (B) PS100 with ( $\square$ ) and without $(\square)$ adenosine. Adenosine at a final concentration of $10 \mathrm{~mm}$ was added at the times indicated by arrows.

TABle I. Growth INHIBITORY EFfects of VARIOUS Purine Derivatives and Analogues

\begin{tabular}{|c|c|c|c|}
\hline \multirow{2}{*}{ Additions } & \multirow{2}{*}{ Concentration } & \multicolumn{2}{|c|}{ Cell growth ${ }^{a}$} \\
\hline & & PS100 & C600 \\
\hline Hypoxanthine & $10 \mu \mathrm{M}$ & - & + \\
\hline Inosine & $10 \mu \mathrm{M}$ & - & + \\
\hline IMP & $10 \mu \mathrm{M}$ & - & + \\
\hline Guanine & $10 \mu \mathrm{M}$ & - & + \\
\hline Guanosine & $10 \mu \mathrm{M}$ & - & + \\
\hline GMP & $10 \mu \mathrm{M}$ & - & + \\
\hline Xanthine & $10 \mu \mathrm{M}$ & - & + \\
\hline Cordycepin & $10 \mu \mathrm{g} / \mathrm{ml}$ & + & + \\
\hline Formycin A & $10 \mu \mathrm{g} / \mathrm{ml}$ & + & + \\
\hline Tubercidin & $10 \mu \mathrm{g} / \mathrm{ml}$ & + & + \\
\hline Purine & $100 \mu \mathrm{M}$ & + & + \\
\hline 6-Thioguanine & $100 \mu \mathrm{M}$ & + & + \\
\hline 6-Thioxanthine & $100 \mu \mathrm{M}$ & + & + \\
\hline
\end{tabular}

a Absorbancy at $610 \mathrm{~nm}$ was measured after $12 \mathrm{hr}$ incubation at $30^{\circ} \mathrm{C}$. + , absorbancy was more than 0.6 ; - , absorbancy was less than 0.06 (no growth).

Other purine derivatives and some purine base and nucleoside analogues were tested as to their inhibitory effect on the growth of PS100. Hypoxanthine, inosine, IMP, guanine, guanosine, GMP and xanthine were all inhibitory for the growth of PS100 at a concentration of $10 \mu \mathrm{M}$ (Table I). Analogues of adenosine such as cordycepin, formycin $\mathrm{A}$ and 
tubercidin were tested at a concentration of $10 \mu \mathrm{g} / \mathrm{ml}$, but none of them showed any effect on the growth of either PS100 or C600. Purine base analogues such as purine, 6-thioguanine and 6-thioxanthine were also tested. None of them showed an inhibitory effect on the cell growth of either PS100 or C600 at a concentration of $100 \mu \mathrm{M}$ (Table I).

\section{Reversal of growth inhibitory effect of adenosine} by pyrimidine derivatives

As stated above, the growth of PS100 was completely inhibited in minimal medium by addition of various kinds of purine derivatives. The growth of PS100 in minimal medium was also investigated with addition of uridine. Addition of this pyrimidine nucleoside at a concentration of less than $10 \mu \mathrm{M}$ did not cause any effect on the growth of PS100, but the growth was stimulated by addition of uridine at more than $100 \mu \mathrm{M}$ concentration (Fig. 2). The generation time of PS100 was $100 \mathrm{~min}$ in the presence of uridine (more than $100 \mu \mathrm{M}$ ), while it was $150 \mathrm{~min}$ in the medium without the addition. This decreased generation time $(100 \mathrm{~min})$ was comparable to that of C600 (100 min). The growth of C600 was not affected at the concentrations of uridine tested (data not shown).

Then uridine was added to the medium for PS100 of which growth was inhibited by addition of adenosine at a concentration of $10 \mu \mathrm{M}$. As shown in Fig. 3, the growth of PS100 was completely inhibited in the absence of uridine. Addition of uridine resulted in recovery of the growth inhibition caused by adenosine $(10 \mu \mathrm{M})$ dependent on the concentration of uridine. The growth of PS100 slightly recovered (generation time, $220 \mathrm{~min}$ ) with addition of $1 \mu \mathrm{M}$ uridine. Growth (generation time, $150 \mathrm{~min}$ ) occurred by addition of $10 \mu \mathrm{M}$ uridine, and the growth rate was comparable to that of PS100 in the medium without addition of adenosine. Addition of uridine at a concentration of $100 \mu \mathrm{M}$ resulted in not only the reversal of growth inhibition but also stimulation of the cell growth (generation time, $100 \mathrm{~min}$ ) in the same way as shown in

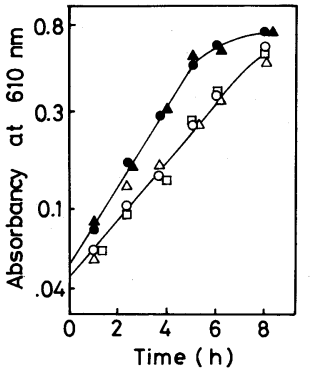

FIG. 2. Growth Curves of PS100 with Addition of Uridine at Various Concentrations.

Cells of PS 100 were cultured in minimal medium at $30^{\circ} \mathrm{C}$ with addition of uridine. Uridine concentrations, $(\mathrm{O})$,

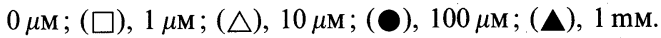

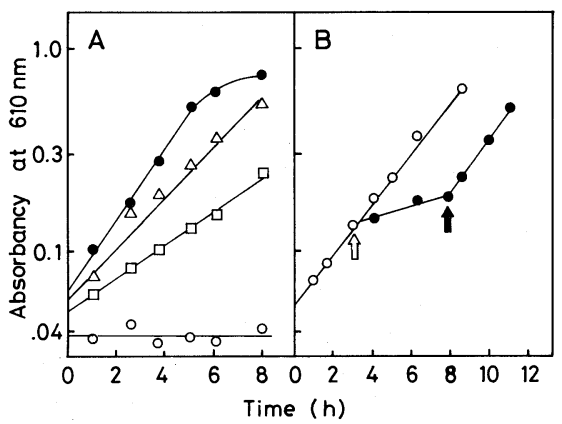

FIG. 3. Growth Curves of PS100 with Co-addition of Adenosine and Uridine.

(A) Cells were cultured in minimal medium containing $10 \mu \mathrm{M}$ adenosine at $30^{\circ} \mathrm{C}$ with co-addition of uridine. Uridine concentrations, $(\bigcirc), 0 \mu \mathrm{M} ;(\square), 1 \mu \mathrm{M} ;(\triangle), 10 \mu \mathrm{M}$; (O), $100 \mu \mathrm{M}$. (B) Cells were cultured in minimal medium at $30^{\circ} \mathrm{C}$ with (O) and without $(\mathrm{O})$ additions. Adenosine at a final concentration of $10 \mu \mathrm{M}$ was added at the time indicated by a white arrow, and uridine at a final concentration of $10 \mu \mathrm{M}$ was further added at the time indicated by a black arrow.

Fig. 2. Addition of $10 \mu \mathrm{M}$ uridine immediately restored the growth of PS100 even after the growth had been inhibited for $5 \mathrm{hr}$ at the logarithmic phase by addition of adenosine $(10 \mu \mathrm{M})$ (Fig. 3B).

Other pyrimidine derivatives and some compounds which are related to the pyrimidine de novo pathway were tested as to their effects on the growth of PS100 which was previously inhibited by adenosine $(10 \mu \mathrm{M})$. The results are shown in Table II. Uracil, uridine, UMP, cytidine and CMP were capable of restoring the 
TABle II. Recovery EfFects of Various

Pyrimidine Derivatives on the Growth OF PS100 INHIBITED BY ADENOSINE

\begin{tabular}{lcc}
\hline \multicolumn{1}{c}{ Additions } & Concentration & ${\text { Cell } \text { growth }^{a}}^{c}$ \\
\hline None & - & - \\
Uracil & $10 \mu \mathrm{M}$ & + \\
Uridine & $10 \mu \mathrm{M}$ & + \\
UMP & $10 \mu \mathrm{M}$ & + \\
Cytosine & $10 \mu \mathrm{M}$ & - \\
& $100 \mu \mathrm{M}$ & + \\
Cytidine & $10 \mu \mathrm{M}$ & + \\
CMP & $10 \mu \mathrm{M}$ & + \\
Thymine & $10 \mu \mathrm{M}$ & - \\
& $100 \mu \mathrm{M}$ & - \\
Thymidine & $10 \mu \mathrm{M}$ & - \\
& $100 \mu \mathrm{M}$ & + \\
Aspartate & $5 \mathrm{~mm}$ & - \\
Orotic acid & $100 \mu \mathrm{M}$ & - \\
NAD & $1 \mathrm{mM}$ & - \\
\hline
\end{tabular}

a Adenosine at a concentration of $10 \mu \mathrm{M}$ was added to all cell cultures. Absorbancy at $610 \mathrm{~nm}$ was measured after $12 \mathrm{hr}$ incubation at $30^{\circ} \mathrm{C}$.

+ , absorbancy was more than 0.6 ; - , absorbancy was less than 0.06 (no growth).

growth of PS100 inhibited by $10 \mu \mathrm{M}$ adenosine. Cytosine and thymidine were also effective, although a higher concentration $(100 \mu \mathrm{M})$ was needed. Thymine was inert as to the recovery even at a concentration of $100 \mu \mathrm{M}$. Aspartate, a precursor, and orotic acid, a metabolic intermediate in the pyrimidine de novo pathway, were not effective for the recovery. Nicotinamide adenine dinucleotide (NAD), a cofactor required for a reaction catalyzed by dihydroorotate dehydrogenase in the pyrimidine de novo pathway, was also ineffective (Table II). All these compounds listed in Table II did not show any influence on the growth of C600 at any concentration tested (data not shown).

Accumulation of orotic acid in culture fluid of mutant strain PS100

When mutant strain PS100 was cultured in minimal medium, UV-absorbing material was accumulated in the culture fluid. In the course of the culture, absorbancy at $260 \mathrm{~nm}$ and $280 \mathrm{~nm}$ (O.D. 260 and O.D. 280) was measured for both PS100 and C600. Time courses of the

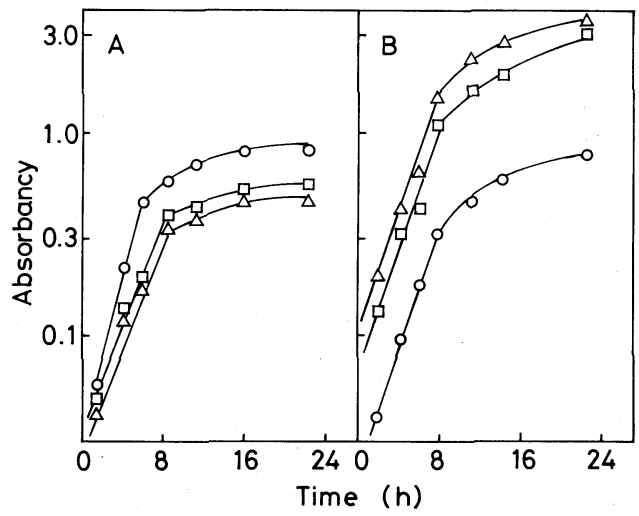

FIG. 4. Accumulation of UV-Absorbing Material in Culture Fluid of PS100.

Cells of (A) C600 and (B) PS100 were grown in minimal medium at $30^{\circ} \mathrm{C}$, and growth was monitored by measuring absorbancy at $610 \mathrm{~nm}$. At the prescribed times, an aliquot of the culture was taken and cells were removed by centrifugation. The resultant supernatant was subjected to absorbancy measurement at 260 and $280 \mathrm{~nm}$. Absorbancy at $610 \mathrm{~nm},(\bigcirc) ; 260 \mathrm{~nm},(\square) ; 280 \mathrm{~nm},(\triangle)$.

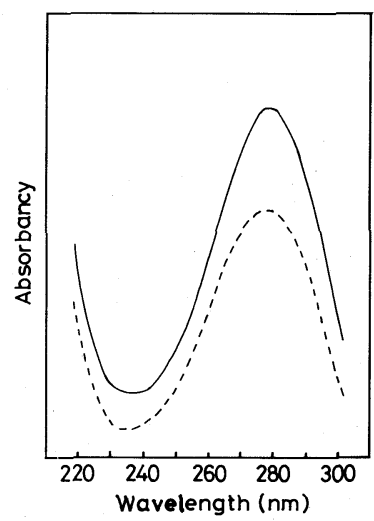

FIG. 5. U $v^{r}$-Spectrum of UV-Absorbing Material Purified from Culture Fluid of PS100.

UV-Absorbing material was purified and crystallized as described in Materials and Methods. Solid line, the purified material; dotted line, authentic orotic acid.

changes in O.D. 260 and O.D. 280 are shown in Fig. 4. The amount of UV-absorbing material increased exponentially in association with the growth of both PS100 and C600. However, marked differences were seen between the patterns of the increase in absorbancy of the two strains. Absorbancy at 260 and $280 \mathrm{~nm}$ of PS100 culture fluid was higher than that of 


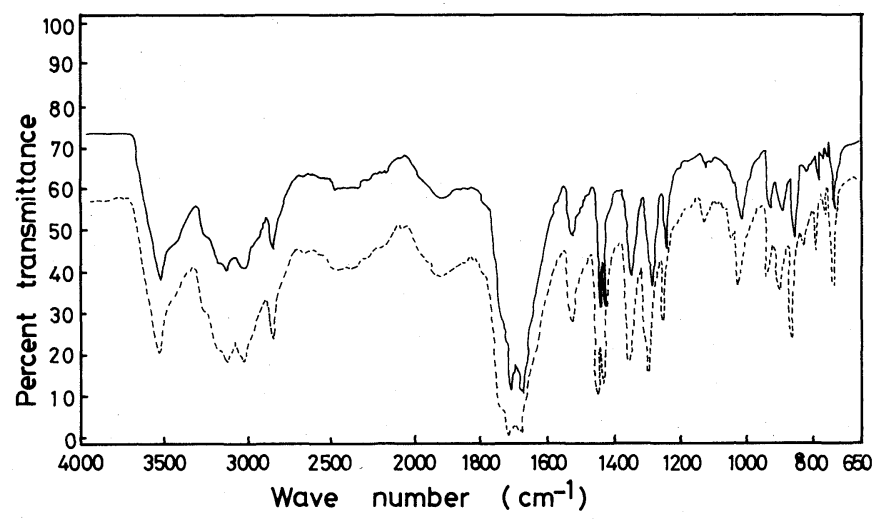

FIG. 6. IR-Spectrum of UV-Absorbing Material Purified from Culture Fluid of PS100.

UV-Absorbing material was purified and crystallized as described in MATERIALS AND METHODS. Solid line, the purified material; dotted line, authentic orotic acid.

C600 during the period tested. At the stationary phase, O.D. 260 and O.D. 280 of PS100 culture fluid reached 3.0 and 3.8 , respectively, while those of $\mathrm{C} 600$ were 0.55 and 0.45 , respectively. Furthermore, the ratio of O.D. 280 to O.D. 260 was 1.4 for PS 100 culture fluid, while the ratio of $\mathrm{C} 600$ was 0.9 during the culture time examined.

The UV-absorbing material was purified from culture fluid of PS100 and identified as orotic acid from the UV-spectrum (Fig. 5), IRspectrum (Fig. 6) and melting point $\left(345^{\circ} \mathrm{C}\right)$.

\section{Decreased level of orotate phosphoribosyltrans-}

ferase activity in mutant strain PS100

The two results that the growth of PS100 was stimulated by addition of some pyrimidine derivatives, and that orotic acid was accumulated in culture fluid of PS100 suggested that a certain enzyme activity was deficient in the pyrimidine de novo pathway. Then enzyme activities of orotate phosphoribosyltransferase (OPT) and orotidine 5'-monophosphate decarboxylase (OMP-DC), which are located between orotic acid and UMP in the metabolic sequence, were assayed. Enzyme activity for OMP-DC of PS100 was a little higher than that of C600 (Table III). On the other hand, enzyme activity for OPT of PS100 was reduced to a lower level $(7 \%)$ compared with that of C600.
TABle III. ENZYME ACTIVITIES FOR OPT AND OMP-DC

\begin{tabular}{|c|c|c|}
\hline \multirow{2}{*}{ Strains } & \multicolumn{2}{|c|}{ Specific activity } \\
\hline & $\mathrm{OPT}^{a}$ & OMP-DC ${ }^{b}$ \\
\hline C600 & 4020 & 0.80 \\
\hline PS 100 & 280 & 1.03 \\
\hline $\operatorname{PS} 100(\lambda-B W 106)^{c}$ & 4070 & 0.98 \\
\hline
\end{tabular}

a Orotate phosphoribosyltransferase (cpm of ${ }^{14} \mathrm{CO}_{2}$ evolved per min per mg-protein).

$b$ Orotidine 5'-monophosphate decarboxylase $(\mu \mathrm{mol}$ per min per mg-protein).

$c$ PS100 lysogenized with $\lambda$-pyrE transducing phage.

To investigate whether the phenotype of purine sensitivity was governed by a single mutation located in the structural gene for OPT (pyrE) or not, the mutant strain was lysogenized with $\lambda$-pyrE transducing phage BW106. ${ }^{10)}$ Lysogenization was checked by thermo-inducible lysis, and the transductant thus obtained was designated as PS100 $(\lambda$ BW106). Enzyme activity for OPT of PS100 ( $\lambda$-BW106) was almost the same level as that of C600 (Table III). Then the growth of PS100 ( $\lambda$ BW106) was examined in minimal medium containing various purine derivatives at a concentration of $10 \mu \mathrm{M}$. The growth of PS100 ( $\lambda$ BW106) was not inhibited by any of the purine derivatives tested, and the generation time (100 $\mathrm{min})$ in minimal medium without addition 
of purine derivatives was comparable to that of C600 (data not shown). Furthermore, a revertant which could grow on minimal agar medium containing adenosine $(20 \mathrm{~mm})$ was obtained spontaneously at a frequency of $5 \sim 10 \times 10^{-7}$. This revertant also retained the same level of OPT activity as that of C600, and its growth was not inhibited by any of the purine derivatives tested (data not shown). These results show that the phenotype of purine sensitivity is caused by a single mutation located in the pyrE gene, which decreases the level of OPT activity to $7 \%$ of the normal level.

\section{DISCUSSION}

An adenosine-sensitive mutant was isolated from Escherichia coli K12 strain C600. This mutant (designated as PS100) was also sensitive to other purine bases, nucleosides and nucleotides (Table I). This growth inhibition caused by adenosine was reversed by coaddition of some pyrimidine derivatives (Table II). Hoshino et al. $^{3)}$ reported that cell growth of an $E$. coli D strain was inhibited by purine bases and nucleosides, and that this inhibition was reversed by co-addition of cytidine, orotic acid and NAD. They suggested that adenosine inhibited the activities of certain enzymes involved in the pyrimidine de novo biosynthetic pathway in the $E$. coli D strain at the stage before orotic acid formation. From the point of growth inhibition, the phenotype of PS100 was similar to that of the $E$. coli D strain, however, marked differences were seen in the following. (1) Cell growth of the $E$. coli D strain was not completely inhibited by addition of purine derivatives. A degree of growth inhibition of 30 to $60 \%$ was reported for various purine bases and nucleosides, while no growth was observed in the case of PS100. (2) Growth inhibition was reversed by neither orotic acid nor NAD in the case of PS100 (Table II).

It was estimated that PS100 was also deficient in certain enzymes involved in the pyrimidine de novo pathway, since the growth of
PS100 was stimulated by addition of uridine (Fig. 2). However, the enzyme deficiency was supposed to be located at the stage after orotic acid formation, since orotic acid was not effective in decreasing the growth inhibition. In fact, orotate phosphoribosyltransferase (OPT) catalyzing a reaction (orotate $+\mathrm{P}-\mathrm{Rib}-\mathrm{PP} \rightarrow$ orotidine 5'-monophosphate $+\mathrm{PPi}$ ) was confirmed as the enzyme deficient in activity. Accumulation of orotic acid in culture fluid of PS100 was presumably due to the deficiency in OPT activity. Enzyme activity of OPT of PS100 decreased to $7 \%$ of the level of C600 (Table III). This low level of OPT activity still permitted the growth of PS100, although the growth rate was reduced (Fig. 1A). Furthermore, genetic analysis revealed that this sensitivity to purine derivatives was caused by a single mutation located in the structural gene for OPT (pyrE).

Machida et al. ${ }^{17,18)}$ reported that in the de novo pathway for pyrimidine synthesis in $E$. coli $\mathrm{K} 12$ the step from orotic acid to 5'-UMP is genetically depressed so that orotic acid (more than $300 \mathrm{mg} /$ liter) is accumulated when pyrimidine compounds are not supplemented. They also reported that the presence of a pyrimidine nucleoside $(5 \mathrm{~mm})$ markedly stimulated growth of $E$. coli K12. It is obscure why E. coli $\mathrm{K} 12$ derivative strain $\mathrm{C} 600$ did not accumulate so much orotic acid and its growth was not stimulated by addition of uridine. However, our observation that mutant PS100 has a decreased level of OPT is coincident with data of Machida et al. ${ }^{17,18)}$

It is ambiguous as to why a decreased level of OPT caused sensitivity to purine compounds. One plausible explanation is that addition of purine derivatives results in decreased availability of P-Rib-PP for the pyrimidine de novo pathway. Bagnara and Finch ${ }^{7)}$ reported that addition of purine precursors depletes the intracellular content of P-Rib-PP to $10 \%$ or less of the normal value in $E$. coli. So this depletion of intracellular P-Rib-PP may cause inhibition of the pyrimidine de novo pathway in the reaction step catalyzed by OPT, since OPT requires P-Rib-PP as a substrate. It is 
probable that the decreased availability of $\mathrm{P}$ Rib-PP causes a drastic inhibition of the OPT reaction in mutant strain PS100 but not in parental strain C600, since in PS100 there is a decreased level of OPT activity due to mutation.

It was well known that both carbamoyl phosphate synthetase and aspartate carbamoyltransferase activity, located in the early stage of the pyrimidine de novo synthetic pathway, are significantly affected by a number of purine and pyrimidine nucleotides. ${ }^{19,20)}$ So there is another possibility that addition of purine derivatives causes inhibition of the pyrimidine de novo pathway at other steps than OPT in mutant strain PS100. Such an inhibition, if it occurs, may block the pyrimidine de novo pathway of PS100 severely, since the flux of the pathway was previously decreased by a decreased level of OPT. In any case, the result that analogues of purine derivatives such as cordycepin, formycin A, tubercidin, purine, 6-thioguanine and 6-thioxanthine did not inhibit the growth of PS100 (Table I), indicates the possibility that growth inhibition is dependent on normal cellular metabolism of exogenous purine derivatives.

Strain PS100 may become a useful tool for obtaining a mutant for exogenous purine metabolism. By positive selection of colonies which can grow on minimal agar plates containing various purine derivatives, mutants deficient in the enzymes for metabolism of corresponding purine compounds may be obtained easily. In fact, adenosine-resistant colonies could be selected from PS100 on minimal agar medium containing adenosine $(20 \mathrm{~mm})$ after NTG treatment (data not shown). Most of them were thought to be revertants, since a normal level of activity for OPT was detected. However, some of them still had a decreased level of OPT activity and growth could still be inhibited by either inosine or guanosine. So this was thought to be a mutant defective in enzymes for adenosine metabolism such as purine nucleoside phosphorylase and adenine phosphoribosyltranferase.
Anyway some unusual state of cellular metabolism concerning the "purine-pyrimidine balance" emerged through a mutation in the structural gene for OPT (pyrE). Further investigation is in progress to clarify this observation.

Acknowledgments. The authors thank Dr. M. Amano for his kind technical assistance in taking IR-spectra. They also thank T. Hayakawa for his kind technical assistance in assaying of OPT. They also express their appreciation to Dr. M. Himeno for his advice on manipulation of the bacteriophage.

\section{REFERENCES}

1) P. Nygaard, Adv. Exp. Med. Biol., 76, 186 (1977).

2) D. L. Hill and R. F. Pittillo, Antimicrob. Ag. Chemother., 4, 125 (1973).

3) J. Hoshino, S. Izumi and T. Sato, J. Gen. Appl. Microbiol., 11, 161 (1965).

4) J. Repentigny, S. Grimard, P. Turgeon and S. Sonea, J. Bacteriol., 91, 2099 (1966).

5) L. Aronow, Biochim. Biophys. Acta, 47, 184 (1961).

6) F. F. Snyder, M. S. Hershfield and J. E. Seegmiller, Cancer Res., 38, 2357 (1978).

7) A. S. Bagnara and L. R. Finch, Eur. J. Biochem., 41, 421 (1974).

8) K. Ishii and H. Green, J. Cell. Sci., 13, 429 (1973).

9) B. D. Davis and E. S. Mingioli, J. Bacteriol., 60, 17 (1950).

10) A. F. Taylor, P. G. Siliciano and B. Weiss, Gene, 9 , 321 (1980).

11) J. H. Miller, "Experiments in Molecular Genetics," Cold Spring Harbor Laboratory, New York, 1972.

12) E. A. Adelberg, M. Mandel and G. C. C. Chen, Biochem. Biophys. Res. Commun., 18, 788 (1965).

13) O. H. Lowry, N. J. Rosebrough, A. L. Farr and R. J. Randall, J. Biol. Chem., 193, 265 (1951).

14) G. K. Brown and W. J. O'Sullivan, Biochemistry, 16, 3235 (1977).

15) K. Iwai and H. Taguchi, J. Nutr. Sci. Vitaminol., 19, 491 (1973)

16) I. Lieberman, A. Kornberg and E. S. Simms, J. Biol. Chem., 215, 403 (1955).

17) H. Machida and A. Kuninaka, Agric. Biol. Chem., 33, 868 (1969).

18) H. Machida, A. Kuninaka and H. Yoshino, Agric. Biol. Chem., 34, 1129 (1970).

19) P. M. Anderson and A. Meister, Biochemistry, 5, 3164 (1966).

20) J. C. Gerhart and A. B. Pardee, J. Biol. Chem., 237, 891 (1962) 